\title{
The Metabolic Syndrome Is a Risk Factor for Breast Cancer: A Systematic Review and Meta-Analysis
}

\author{
Ping Zhao ${ }^{a}$ Ning Xia ${ }^{a}$ Hong Zhang ${ }^{b}$ Tingting Deng ${ }^{b}$ \\ ${ }^{a}$ Guangxi Medical University, Nanning, PR China; ${ }^{b}$ Department of Endocrinology, Fourth \\ Affiliated Hospital of Guangxi Medical University, Nanning, PR China
}

\section{Keywords}

Metabolic syndrome $\cdot$ Breast cancer $\cdot$ Menopausal status $\cdot$ Risk of breast cancer

\begin{abstract}
Background: The metabolic syndrome (MetS) has been associated with the pathogenesis and prognosis of various malignant tumors. In this systematic review and meta-analysis, we explored the relationship between MetS and breast cancer (BC). Methods: Relevant studies were systematically searched on Ovid MEDLINE, Embase, Cochrane database, and PubMed up to September 16, 2019, using "breast cancer" and "metabolic syndrome" as keywords. Eligible studies with clear definition of MetS, available data, and relationships between MetS and BC were evaluated using a risk ratio (RR) and its $95 \%$ confidence interval $(\mathrm{Cl})$. Results: Twenty-five studies, including 13 cohort studies and 12 case-control studies, met the inclusion criteria, which assessed a total of 392,583 female participants and 19,628 BC patients. The results revealed a statistically significant increase by $52 \%$ of the risk of $B C$ in adult females with MetS $(\mathrm{RR}=1.49,95 \% \mathrm{Cl}=1.31-1.70, p<0.0001)$. Postmenopausal MetS patients may have a twofold risk to suffer $B C(R R=2.01,95 \% \mathrm{Cl}=1.55-2.60, p<0.001)$. The risk of $B C$ increased markedly with the number of MetS components: $\mathrm{RR}=1.00$ for 1 component $(p=0.976), \mathrm{RR}=1.40$ for 2 components $(p=0.121)$, and $\mathrm{RR}=1.98$ for $>3$ components $(p<0.001)$. The risk factors associated with $B C$ were obesity, hypertension, and diabetes $(R R=1.33,1.19$, and 1.30 respectively, all $p<0.001)$. Conclusions: Our study demonstrated that MetS is highly related with $B C$. In postmenopausal patients with $\geq 2$ MetS components or a combination of obesity, hypertension, and diabetes, routine $B C$ screening could help to detect $B C$ at an early stage.
\end{abstract}




\section{Introduction}

Breast cancer (BC) is a common malignancy of which the incidence ranks first in women, and second in both men and women. Also, it is the leading cause of tumor-related death in women and the fifth of that in the general population around the world [1]. In Western countries, a woman's lifetime risk of developing BC is $12 \%$ [2]. Asian countries have a lower prevalence than Western countries, but due to the shift of lifestyle to Western countries, it shows an increasing trend in recent years $[3,4]$. Studies have found that the occurrence of $\mathrm{BC}$ was not only related to the traditional risk factors such as age, family history, birth history, and menstrual history, but also to obesity, diabetes, and dyslipidemia [5].

The metabolic syndrome (MetS) is a series of metabolic abnormalities characterized by insulin resistance [6], with main components including obesity, hyperglycemia, hyperinsulinemia, dyslipidemia, and hypertension, which promote the development and progression of type 2 diabetes and cardiovascular diseases [6]. The concept and definition of MetS first appeared in 2001, and its content was constantly revised as research progressed [7]. Due to ethnic differences and diagnostic criteria, MetS incidence varies widely from region to region. In developed countries, the incidence is $22-39 \%$ [8]. According to a survey by the National Health and Nutrition Examination Surveys in the United States, the incidence of MetS in people over 20 years is $31.9 \%$ (30.6\% for men and $33.2 \%$ for women) [9]. A study conducted in China found an incidence of $27.4 \%$ (27.9\% for men and $26.8 \%$ for women) [10]. MetS has gradually become a public health problem that cannot be ignored in some countries with high obesity and Western diet patterns [11]. Studies have shown that the incidence and mortality of cardiovascular diseases in people who fulfill the diagnostic criteria is about 2-3 times higher than in those without MetS [11].

Recently, MetS has been found to be associated with the pathogenesis and prognosis of various malignant tumors $[12,13]$. A large number of studies have also confirmed that multiple components of MetS are closely related to the occurrence and development of BC $[14,15]$. The main components (central obesity, hyperglycemia, dyslipidemia, and hypertension) can affect the occurrence and prognosis of BC through various mechanisms [16]. However, some other studies suggested that the number of components is not only related to the risk of $\mathrm{BC}$ [17], some studies even suggested that the occurrence of both MetS and BC increase with age, and thus menopausal status may be a reason for the relationship between both diseases [18]. Based on the large-scale studies reported in recent years, we designed and conducted a systematic review and meta-analysis to explore the relationship between MetS and BC.

\section{Methods}

This study was performed in accordance with the preferred reporting items for systematic review and meta-analysis (PRISMA) guidelines [19].

\section{Search Strategy}

This study aimed to explore the relationship between MetS and the occurrence and prevalence of BC. A systematic search was conducted on Ovid MEDLINE, Embase, Cochrane Database of Systematic Reviews and Cochrane Central Register of Controlled Trials, and PubMed (up to September 16, 2019). Besides, Google Scholar and other related websites and databases were also searched for gray literature. For the search, we used medical terms and related extended versions: "breast neoplasm," "breast carcinoma," "breast cancer," and

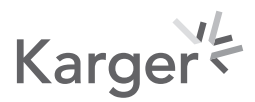


Zhao et al.: MetS Is a Risk Factor for BC

"metabolic syndrome." The studies containing abstracts and titles were all imported into EndNote (Clarivate Analytic, version X5) to find duplicate studies and then for literature screening.

\section{Inclusion and Exclusion Criteria}

All the studies mentioning and discussing the relationship between MetS and BC were included in our review. Inclusion criteria were: (1) MetS was clearly defined; (2) the data of occurrence of breast malignancy could be extracted using events or hazard ratio (HR) or odds ratio (OR); and (3) the study design was limited to prospective or retrospective cohort studies, and case-control studies. The other meta-analyses, reviews, conference abstracts, and comments were read for further inclusion. Only papers in English language were included in our systematic review.

Exclusion criteria were: (1) animal experiments; (2) no clear definition of MetS; (3) no available data of the relationship between MetS and BC; (4) not limited to BC; (5) case reports, or non-English language studies. Data from the same institution would be included only once for further meta-analysis.

\section{Literature Screening and Data Extraction}

Two investigators (P.Z. and H.Z.) independently screened the abstracts and titles based on the inclusion and exclusion criteria. Full texts were further evaluated when the selection could not be made by abstracts. The third investigator (X.N.) was consulted for discussion in case of any disagreement.

The data were extracted into a standard Excel file which included study characteristics (e.g., author, year of publication, country, institution, recruitment period, and study design), $\mathrm{BC}$ type and stage, MetS definition and components, patient characteristics (median age and menopausal status), HR or OR which resulted from MetS, and the occurrence of BC in MetS and non-MetS patients.

\section{Quality Assessment}

Two reviewers (P.Z. and T.Z.) independently assessed the quality of the papers enrolled. For case-control and cohort studies, the Newcastle-Ottawa Scale was used for quality evaluation. High quality was defined as a score $>7$, and moderate quality was defined as a score of 5-7 [20]. Moreover, the Grading of Recommendations, Assessment, Development, and Evaluation (GRADE) system was used to evaluate the overall quality of the evidence [21].

\section{Definition of MetS}

Currently, the most common definition of MetS is in accordance with NCEP (National Cholesterol Education Program) ATP III (Adult Treatment Panel III). MetS has been defined as: (1) waist circumference $>88 \mathrm{~cm}$; (2) triglycerides (TG) $\geq 150 \mathrm{mg} / \mathrm{dL}$; (3) decreased highdensity lipoprotein cholesterol (HDL-C) levels (female $<50 \mathrm{mg} / \mathrm{dL}$ ); (4) elevated blood pressure (systolic $\geq 130 \mathrm{~mm} \mathrm{Hg}$ and/or diastolic $\geq 85 \mathrm{~mm} \mathrm{Hg}$ ); (5) fasting blood glucose $\geq 100$ $\mathrm{mg} / \mathrm{dL}$, or undergoing therapy [7]. However, some other studies adapted the modified NCEP ATP III definition. For example, Watanabe et al. [12] followed the definition of MetS as body mass index (BMI) $\geq 25 \mathrm{~kg} / \mathrm{m}^{2}$ and the presence of $\geq 2$ of the following criteria: (1) systolic and/or diastolic blood pressure $\geq 130 / 85 \mathrm{~mm} \mathrm{Hg}$ or the use of antihypertensive medication; (2) TG $\geq 150 \mathrm{mg} / \mathrm{dL}$ and/or HDL-C $<40 \mathrm{mg} / \mathrm{dL}$ and/or the use of antihyperlipidemic medication; (3) fasting blood glucose $\geq 110 \mathrm{mg} / \mathrm{dL}$ (with a fasting duration of $\geq 3 \mathrm{~h}$ ), or casual blood glucose (for $<3 \mathrm{~h}$ or without regard to the time since the last meal) $\geq 140 \mathrm{mg} / \mathrm{dL}$ and/or the use of antidiabetic medication. In some Chinese studies, experts defined the cutoff of waist circumference as $80 \mathrm{~cm}$ for females [17].

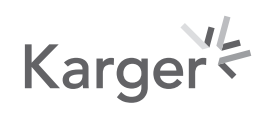


Fig. 1. Flowchart of the studies included.

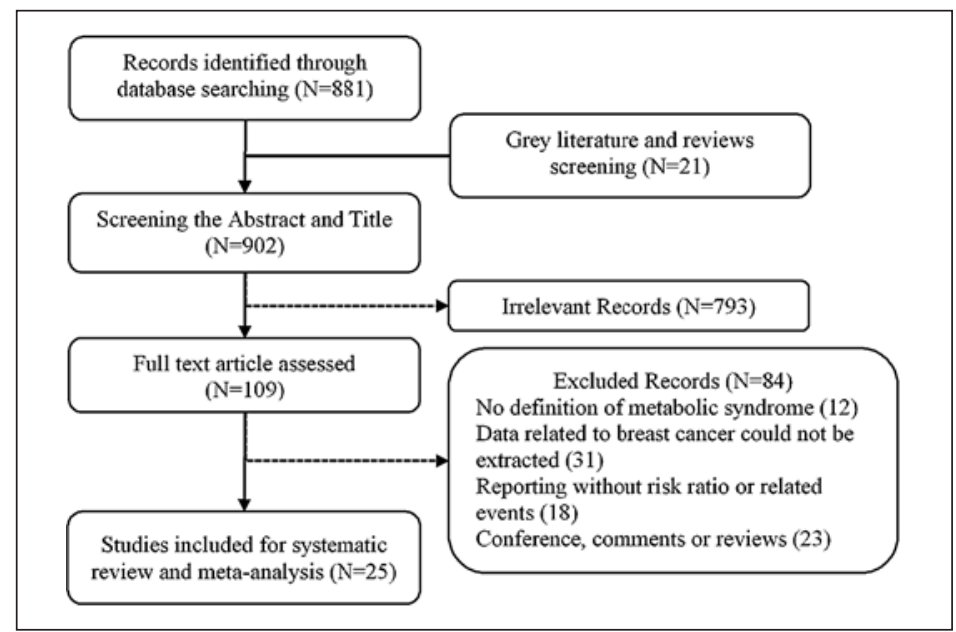

\section{Statistical Analysis}

HR from cohort studies and the OR from the case-control studies were combined in a forest plot using the meta-analysis method, and their risk ratios (RR) were calculated. Both ratios were reported with $95 \%$ confidence intervals (CI), and a $p$ value $<0.05$ was considered statistically significant. The $I^{2}$ statistic and $\chi^{2}$ test were used for heterogeneity assessment $\left(I^{2} \geq 50 \%\right.$ indicating presence of heterogeneity). When heterogeneity existed, a randomeffect model was used; or a fix-effect model was adopted. Finally, forest plots were drawn, and funnel plots were used to evaluate publication bias. Statistical analysis was performed by Stata 15.0 software (Stata Corporation, College Station, TX, USA).

\section{Results}

\section{Literature Selection}

The search identified 881 studies. The flowchart is shown in Figure 1. Among these, after first screening of the titles and abstracts, 109 studies were further assessed in full text. In accordance with the inclusion and exclusion criteria, 25 studies were finally enrolled [12-18, 22-39].

\section{Characteristics of the Selected Studies and Quality Assessment}

The characteristics of the studies included are shown in Tables 1 and 2 . There were 13 cohort studies (Table 1), of which 5 were conducted in the USA, 3 in Korea, 2 in Japan, and the remaining 3 in the Netherlands, Italy, and France, respectively. These 13 studies involved a total of 330,403 female participants, and among them 8,569 were diagnosed with BC from 1986 to 2010. Follow-up ranged from 5.5 to 18.5 years to achieve a higher recall rate. Besides, the cohort studies were all adjusted with variables to calculate HR. The case-control studies are listed in Table 2. There were 12 studies with 62,180 participants enrolled. Among them, 11,059 patients were diagnosed with BC. The quality assessments are available in Tables 1 and 2 for cohort stud and case-control studies, respectively, with scores ranging from 5 to 8 on the Newcastle-Ottawa Scale. Nine studies were considered high quality, with a score of 8 , and the remaining 17 studies were evaluated as median quality. According to the GRADE system, due to lack of randomized controlled trials, the overall quality of MetS evidence as a predictive factor for BC should be considered "very low." 


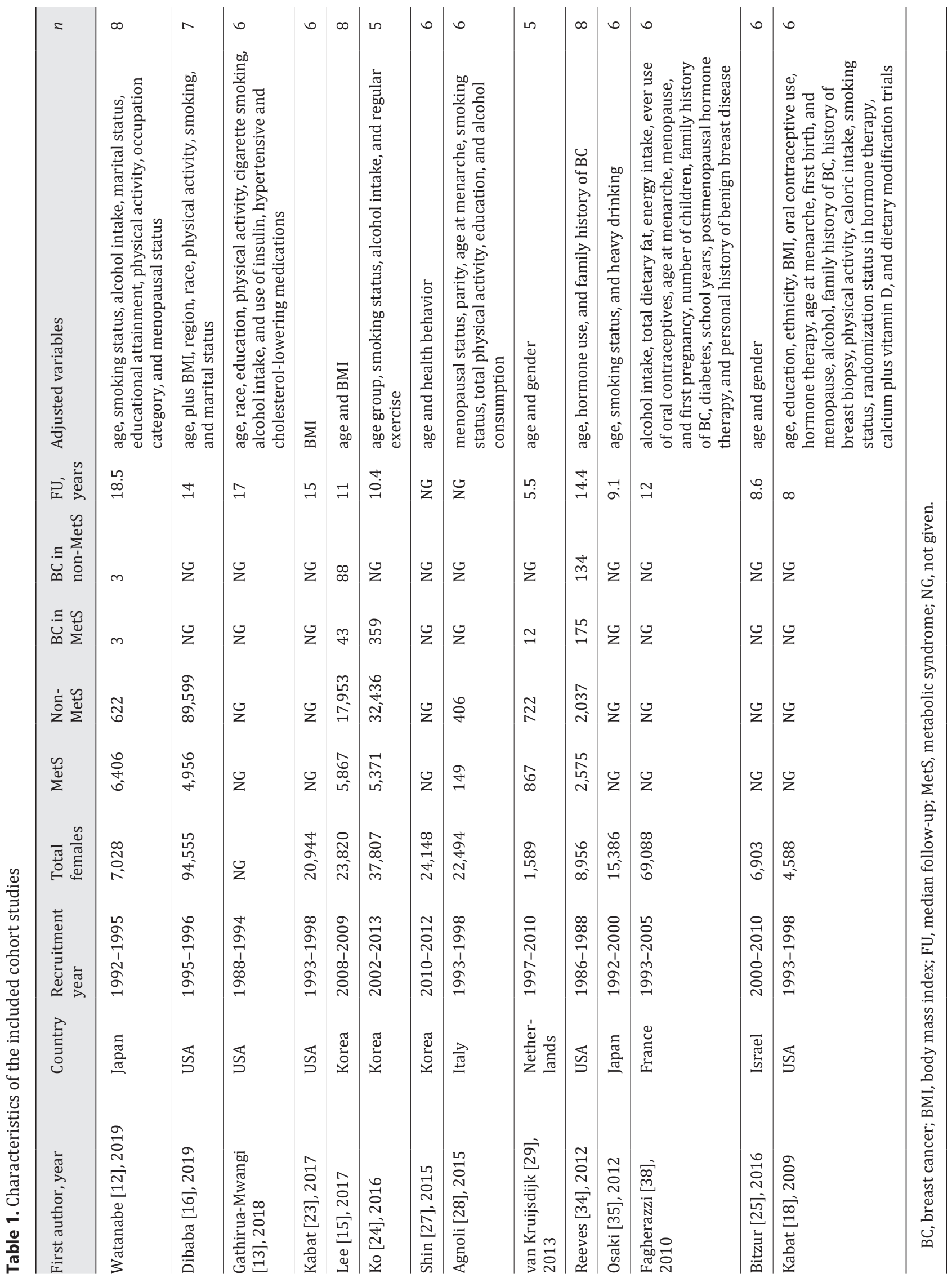




\begin{tabular}{|c|c|}
\hline Dbes Facts 2020;13:384-396 & \\
\hline DOI: 10.1159/000507554 & $\begin{array}{l}\text { (c) } 2020 \text { The Author(s). Published by S. Karger AG, Basel } \\
\text { www.karger.com/ofa }\end{array}$ \\
\hline
\end{tabular}

Table 2. Characteristics of included case-control studies

\begin{tabular}{|c|c|c|c|c|c|c|c|c|}
\hline First author, year & Country & $\begin{array}{l}\text { Recruitment } \\
\text { year }\end{array}$ & $\begin{array}{l}\text { Total } \\
\text { females }\end{array}$ & $\mathrm{BC}$ & Non-BC & $\begin{array}{l}\text { MetS } \\
\text { in } B C\end{array}$ & $\begin{array}{l}\text { MetS in } \\
\text { non-BC }\end{array}$ & $n$ \\
\hline Wu [17], 2018 & China & 2015-2017 & 3,807 & 605 & 3,212 & 197 & 504 & 8 \\
\hline Fang [22], 2018 & China & 2012-2016 & 3,080 & 1,540 & 1,540 & 383 & 429 & 8 \\
\hline Park [14], 2017 & Korea & 2004-2013 & 2,920 & 584 & 2,336 & 76 & 628 & 8 \\
\hline Wang [26], 2015 & China & 2011-2013 & 129 & 43 & 86 & 17 & 18 & 7 \\
\hline Noh et al. [30], 2013 & Korea & 1995-2001 & 810 & 270 & 429 & 69 & 111 & 8 \\
\hline Capasso [31], 2013 & Italy & 2008-2011 & 975 & 410 & 565 & 109 & 81 & 8 \\
\hline Buttros [32], 2013 & Brazil & 2011 & 312 & 104 & 208 & 52 & 78 & 8 \\
\hline Ronco [33], 2012 & Uruguay & 2004-2009 & 912 & 367 & 545 & $\mathrm{NG}$ & NG & 5 \\
\hline Rosato [36], 2011 & Italy & 1983-2007 & 7,851 & 3,869 & 4,082 & NG & NG & 5 \\
\hline Bordeleau [37], 2011 & Canada & 1982-2009 & 6,052 & $N G$ & NG & NG & NG & 6 \\
\hline Chen [39], 2004 & China & 1996-1998 & 28,429 & NG & NG & NG & NG & 6 \\
\hline
\end{tabular}

NG, not given; MetS, metabolic syndrome; BC, breast cancer.

\begin{tabular}{|c|c|c|c|}
\hline \multicolumn{2}{|l|}{$\begin{array}{l}\text { Study } \\
\text { ID }\end{array}$} & \multirow[t]{2}{*}{$\mathrm{ES}(95 \% \mathrm{Cl})$} & \multirow[t]{2}{*}{$\begin{array}{l}\% \\
\text { Weigh }\end{array}$} \\
\hline cohort study & $!$ & & \\
\hline Agnoli, C. (2015) [28] & 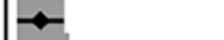 & $1.50(1.14,1.97)$ & 5.36 \\
\hline Bitzur, R. (2016) [25] & & $1.67(1.05,2.67)$ & 3.71 \\
\hline Dibaba, D. T. (2019) [16] & 7 & $1.73(1.09,2.75)$ & 3.73 \\
\hline Kabat, G. C. (2017) [18] & 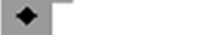 & $1.28(1.13,1.44)$ & 6.60 \\
\hline Ko, S. (2016) [24] & $\rightarrow-$ & $1.27(0.95,1.69)$ & 5.23 \\
\hline Lee, J. A. (2017) [15] & & $1.50(1.04,2.16)$ & 4.53 \\
\hline Osaki, Y. (2012) [35] & - & $2.87(1.67,4.94)$ & 3.18 \\
\hline Reeves, K. W. (2012) [34] & & $1.30(1.01,1.68)$ & 5.53 \\
\hline Van Kruijsdijk, R. C. M. (2013) [29] & & $0.73(0.31,1.76)$ & 1.72 \\
\hline Watanabe, J. (2019) [12] & & $11.90(2.25,62.84)$ & 0.57 \\
\hline Subtotal (I-squared $=54.1 \%, p=0.021$ ) & & $1.48(1.25,1.74)$ & 40.15 \\
\hline . & & & \\
\hline case-control study & & & \\
\hline Bordeleau, L. (2011) [37] & & $1.90(1.30,2.60)$ & 4.70 \\
\hline Buttros Dde, A. (2013) [32] & & $1.66(1.04,2.68)$ & 3.66 \\
\hline Capasso, I. (2013) [31] & & $2.16(1.57,2.98)$ & 4.93 \\
\hline Chen, T. H. (2004) [39] & & $1.86(0.37,9.39)$ & 0.60 \\
\hline Fang, Q. (2018) [22] & & $0.86(0.73,1.01)$ & 6.32 \\
\hline Gathirua-Mwangi, W. G. (2018) [13] & 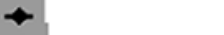 & $1.17(0.99,1.37)$ & 6.31 \\
\hline Kabat, G. C. (2017) [23] & $\bullet$ & $1.21(1.08,1.37)$ & 6.61 \\
\hline Lee, J. A. (2017) [15] & $\Leftrightarrow$ & $1.52(1.01,2.28)$ & 4.17 \\
\hline Noh, H. M. (2013) [30] & & $0.98(0.69,1.39)$ & 4.66 \\
\hline Rosato, V. (2011) [36] & - & $1.75(1.37,2.22)$ & 5.65 \\
\hline Shin, J. Y. (2015) [27] & & $1.49(1.00,2.23)$ & 4.22 \\
\hline Wang, M. (2015) [26] & & $2.47(1.11,5.51)$ & 1.93 \\
\hline Wu, Y. T. (2018) [17] & $1 \rightarrow$ & $2.17(1.79,2.63)$ & 6.08 \\
\hline Subtotal (l-squared $=85.4 \%, p=0.000)$ & $\diamond$ & $1.49(1.22,1.81)$ & 59.85 \\
\hline . & A & & \\
\hline Overall (I-squared $=78.5 \%, p=0.000)$ & () & $1.49(1.31,1.70)$ & 100.00 \\
\hline NOTE: Weights are from random effects analysis & I & & \\
\hline$T$ & $T$ & & \\
\hline 1 & 10 & & \\
\hline
\end{tabular}

Fig. 2. Forest plot assessing the risk of breast cancer incidence associated with the metabolic syndrome according to the study type (cohort study or case-control study). 


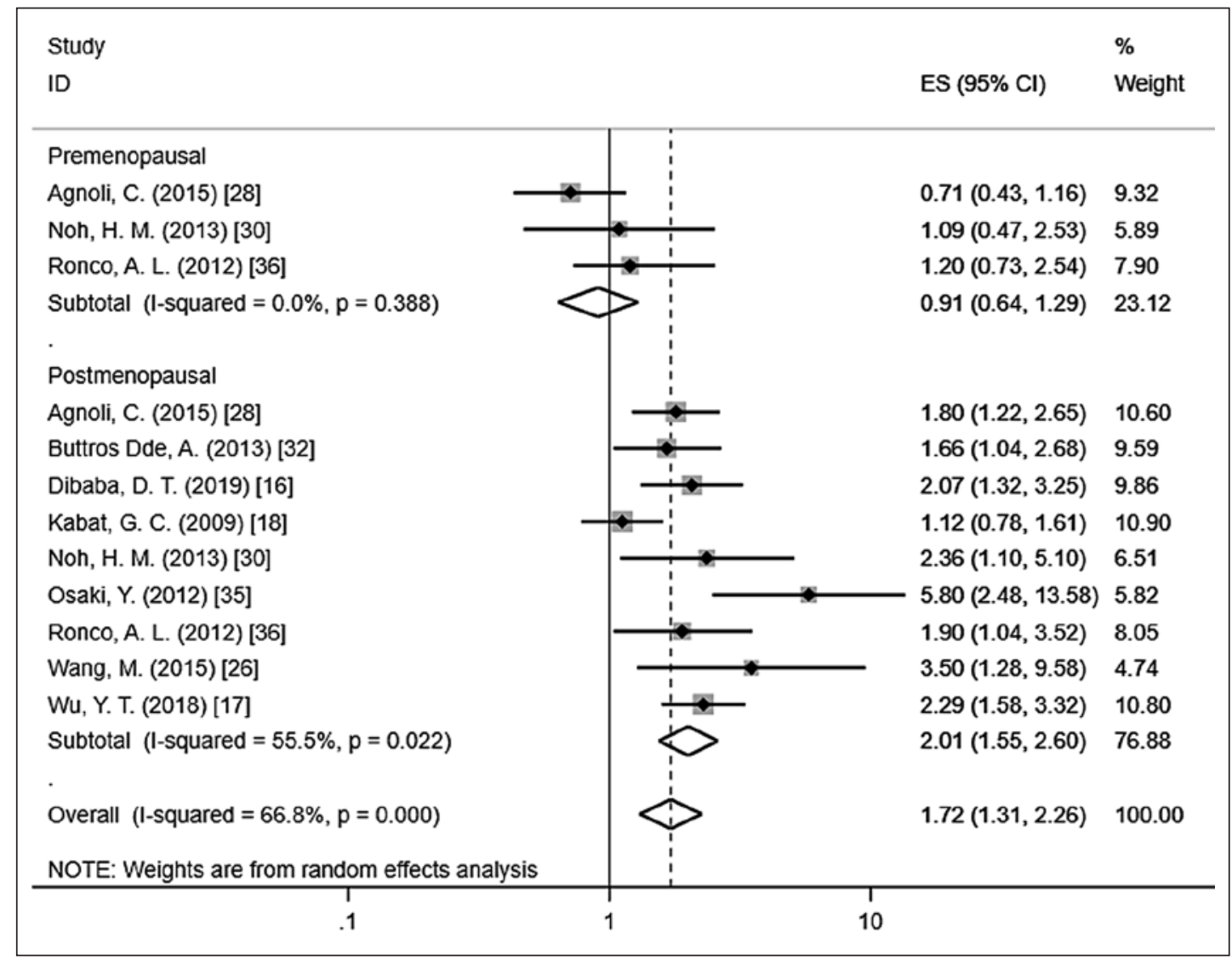

Fig. 3. Forest plot assessing the risk of breast cancer associated with the metabolic syndrome with respect to the menopausal status (pre- or postmenopausal).

\section{Meta-Analysis of Whole Studies}

The forest plot of whole studies is shown in Figure 2. Overall, the risk for BC was increased by $49 \%$ in adult females with MetS and considered statistically significant and with moderate heterogeneity $\left(\mathrm{RR}=1.49,95 \% \mathrm{CI}=1.31-1.70, p<0.0001, I^{2}=78.8 \%\right.$, random effect model). When 1 study was excluded, $I^{2}$ would decrease to $70.5 \%$, with a slight increase in RR (1.56) [22]. Besides, due to using different methods to calculate RR, we divided the studies into cohort and case-control studies. In cohort studies, female MetS patients may have a 1.55-fold risk for developing BC during the follow-up $\left(\mathrm{RR}=1.48,95 \% \mathrm{CI}=1.25-1.74, p<0.0001, I^{2}=\right.$ $54.1 \%$, random effect model). Similarly, in case-control studies, BC patients may have a higher risk for developing MetS $\left(\mathrm{RR}=1.49,95 \% \mathrm{CI}=1.22-1.81, p<0.0001, I^{2}=85.4 \%\right.$, random effect model).

There were 3 studies comparing the relationship between MetS and BC types. Two of them discussed the relationship between MetS and estrogen receptor-positive BC. However, no significant relationship was found due to the small sample size $(\mathrm{RR}=1.59,95 \% \mathrm{CI}=0.65$ $3.89, p=0.310, I^{2}=80.9 \%$, random effect model).

\section{The Impact of Menopausal Status on BC Incidence}

In terms of the menopausal status, the relationship between MetS and the incidence of $\mathrm{BC}$ is shown in Figure 3. There was no significant relationship between $\mathrm{BC}$ and MetS when patients were in the premenopausal period $\left(\mathrm{RR}=0.91,95 \% \mathrm{CI}=0.64-1.29, p=0.580, I^{2}=0 \%\right.$, 
Zhao et al.: MetS Is a Risk Factor for BC

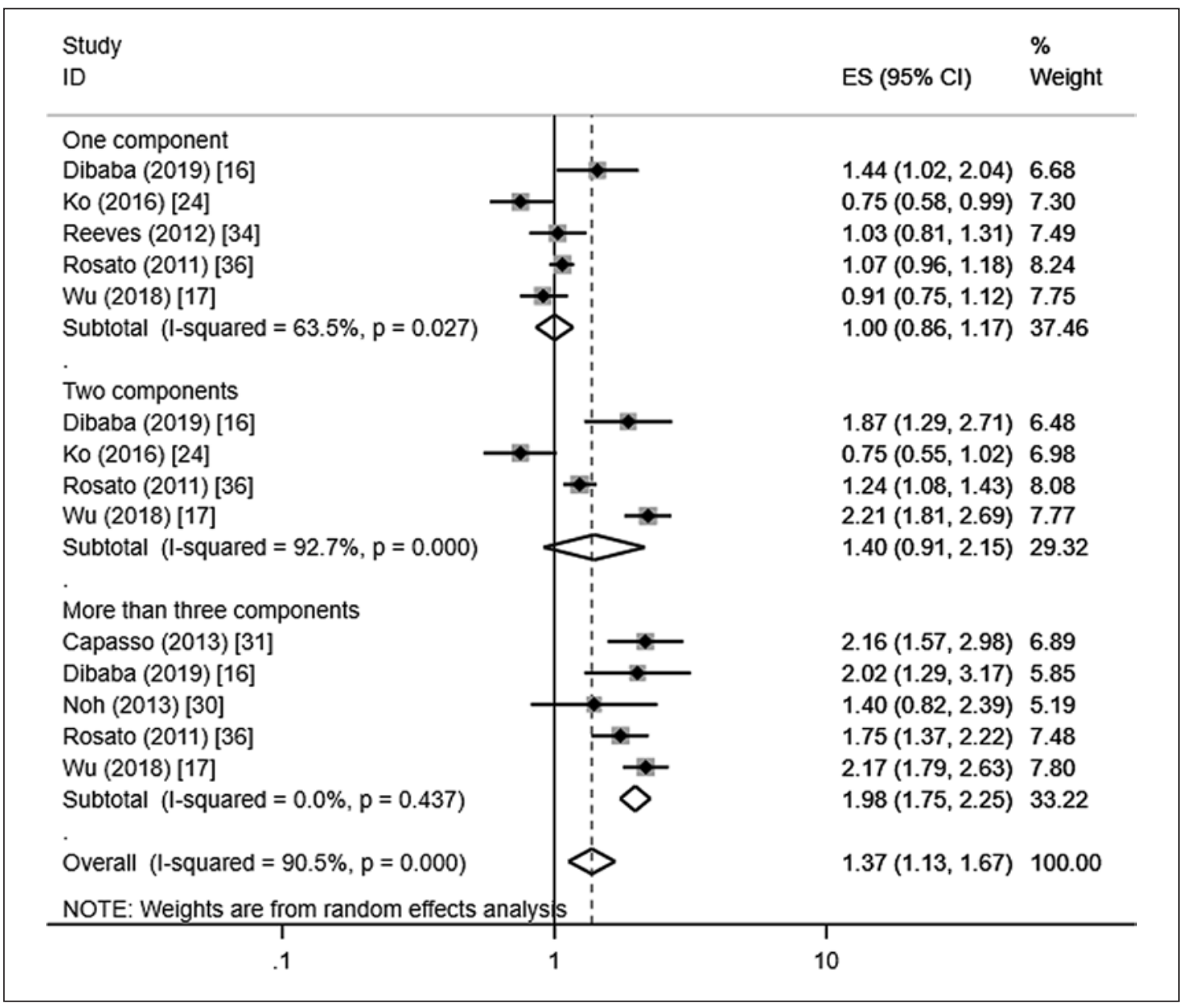

Fig. 4. Forest plot assessing the risk of breast cancer associated with the number of metabolic syndrome components $(1,2$, or $>3$ risk factors $)$.

random effect model). However, in postmenopausal females, MetS may induce a twofold risk to suffer BC, which is without heterogeneity $\left(\mathrm{RR}=2.01,95 \% \mathrm{CI}=1.55-2.60, p<0.0001, I^{2}=\right.$ $55.5 \%$, random effect model).

The Impact of Components of MetS on BC Incidence

Analyses of different MetS component subgroups are depicted in Figure 4. When patients had 1 MetS component, there appeared no significant relationship between MetS and the incidence of $\mathrm{BC}\left(\mathrm{RR}=1.00,95 \% \mathrm{CI}=0.86-1.17, p=0.976, I^{2}=63.5 \%\right.$, random effect model $)$. However, when patients had 2 components of MetS, the risk of BC increased markedly, i.e., 1.40 -fold compared to patients without MetS, but no statistically significant difference and a high heterogeneity were demonstrated $\left(\mathrm{RR}=1.40,95 \% \mathrm{CI}=0.91-2.15, p=0.121, I^{2}=92.7 \%\right.$, random effect model). Moreover, when patients had $>3$ components of MetS, the incidence of $\mathrm{BC}$ was significantly increased versus patients without MetS, without any heterogeneity (RR $=1.98,95 \% \mathrm{CI}=1.75-2.25, p<0.001, I^{2}=0 \%$, fixed effect model $)$.

Next, we analyzed the association between different MetS components and the incidence of BC, and results are shown in Table 3. Patients with obesity or higher BMI may have a higher incidence of $\mathrm{BC}(\mathrm{RR}=1.33,95 \% \mathrm{CI}=1.14-1.56, p<0.001)$. Besides, patients with high blood pressure or diabetes also had a higher risk of developing $\mathrm{BC}(\mathrm{RR}=1.19$ and $1.30,95 \% \mathrm{CI}=$ 
Table 3. The risk of individual components of the metabolic syndrome to affect the development of breast cancer

\begin{tabular}{|c|c|c|c|c|c|c|}
\hline Disease & Study type & $\begin{array}{l}\text { Studies, } \\
n\end{array}$ & HR/OR & $95 \% \mathrm{CI}$ & $p$ & $I^{2}, \%$ \\
\hline \multirow[t]{3}{*}{ BMI $>25$ or obesity } & all & 9 & 1.33 & $1.14-1.56$ & $<0.001$ & 60.7 \\
\hline & cohort study & 3 & 1.57 & $1.14-2.16$ & 0.005 & 57.6 \\
\hline & case-control study & 6 & 1.22 & $1.04-1.43$ & 0.018 & 46.1 \\
\hline \multirow[t]{3}{*}{ Higher waist circumference } & all & 7 & 1.388 & $0.72-2.62$ & 0.329 & 97.8 \\
\hline & cohort study & 3 & 1.02 & $0.74-1.39$ & 0.919 & 64.9 \\
\hline & case-control study & 4 & 1.77 & $0.63-4.94$ & 0.279 & 98.7 \\
\hline \multirow[t]{3}{*}{ High triglycerides } & all & 10 & 1.01 & $0.89-1.15$ & 0.873 & 41.4 \\
\hline & cohort study & 3 & 1.13 & $0.87-1.46$ & 0.377 & 0.0 \\
\hline & case-control study & 7 & 0.99 & $0.84-1.17$ & 0.889 & 56.1 \\
\hline \multirow[t]{3}{*}{ Low high-density lipoprotein } & all & 6 & 1.22 & $1.07-1.40$ & 0.003 & 0.0 \\
\hline & cohort study & 2 & 0.97 & $0.50-1.89$ & 0.928 & 51.4 \\
\hline & case-control study & 4 & 1.24 & $1.08-1.43$ & 0.002 & 0.0 \\
\hline \multirow[t]{3}{*}{ High blood pressure } & all & 14 & 1.19 & $1.09-1.31$ & $<0.001$ & 38.8 \\
\hline & cohort study & 5 & 1.18 & $1.06-1.33$ & 0.004 & 0.0 \\
\hline & case-control study & 9 & 1.20 & $1.05-1.38$ & 0.009 & 54.6 \\
\hline \multirow{3}{*}{$\begin{array}{l}\text { High fasting blood glucose or } \\
\text { diabetes }\end{array}$} & all & 10 & 1.30 & $1.16-1.44$ & $<0.001$ & 86.3 \\
\hline & cohort study & 4 & 1.25 & $1.02-1.54$ & 0.035 & 0.0 \\
\hline & case-control study & 6 & 1.31 & $1.16-1.49$ & $<0.001$ & 0.0 \\
\hline
\end{tabular}

1.09-1.31 and 1.16-1.44, respectively, both $p<0.001$ ). The subgroups of cohort and casecontrol studies also demonstrated increased risks of developing BC with respect to obesity, hypertension, and diabetes. Low high-density lipoprotein level was associated with an increased risk of BC in all the studies $(p=0.003)$, while no statistical significance was found in cohort studies due to small sample sizes. High waist circumference and high triglyceride levels did not result in a significantly increased BC incidence ( $p=0.329$ and $p=0.873$ ).

\section{Discussion}

This is the largest-scale systematic review which included 25 studies with 392,583 female participants and 19,628 BC patients. Our meta-analysis demonstrated that MetS increased the risk of BC. Moreover, as the number of MetS components increased, the patients had a higher BC incidence rate during the follow-up, especially in postmenopausal patients. In these patients, the incidence of $\mathrm{BC}$ was twofold increased compared to those without MetS. In this study, we also discussed which components were the most important risk factor, and demonstrated that obesity, hypertension, and diabetes were all independently associated with a higher incidence of $\mathrm{BC}$.

Obesity, especially central obesity, is an important component of MetS. Studies have shown that an increased BMI can rise the incidence of BC in postmenopausal women and protect women in the premenopausal period [40,41]. However, there are also studies suggesting that obesity increased the risk of $\mathrm{BC}$ in women, regardless of whether they entered menopause or not $[42,43]$. Some studies suggested the risk of developing BC not only associated with obesity, but also with the obesity phenotype [23, 44]. Kabat et al. [23] compared different obesity phenotypes and found that both patients with metabolic healthy obesity and patients with metabolic unhealthy obesity were at an increased risk of developing BC. The RR 
for the former was 1.31 and 1.61 for the latter in a total of 19,819 patients included. However, another research with 50,884 participants from the Sister Study showed that patients with metabolic healthy obesity did not have a significantly increased incidence of $\mathrm{BC}(\mathrm{RR}=1.14$, $95 \% \mathrm{CI}=0.95-1.37$ ), while those with metabolic unhealthy obesity had a 1.28-fold risk, with a statistically significant difference $(\mathrm{RR}=1.28,95 \% \mathrm{CI}=1.12-1.48)$ [44]. Moreover, the study also showed an increase in $\mathrm{BC}$ development among postmenopausal patients with unhealthy metabolic components but a normal BMI (RR $=1.26,95 \% \mathrm{CI}=1.01-1.56)$. Nevertheless, the impact of the obesity phenotype on the incidence of $\mathrm{BC}$ was still controversial. More cohort and case-control studies need to be undertaken in terms of the phenotype and duration of obesity.

Diabetes was another essential MetS component associated with the incidence of BC. A longitudinal study of 5,450 postmenopausal women followed up for 8 years reported that women with high serum insulin and blood glucose levels had a twofold increased risk of BC in the highest tertile compared to the lowest group [45]. Besides, a meta-analysis of 18 retrospective studies and 22 prospective studies conducted by Boyle et al. [46] showed that women with type 2 diabetes had a $27 \%$ increased risk of developing BC. In terms of dyslipidemia, a prospective study undertaken by Kitahara et al. [47] showed that serum total cholesterol $>240 \mathrm{mg} / \mathrm{dL}$ was associated with an increased incidence of BC compared to those $<160 \mathrm{mg} /$ dL. Furberg et al. [48] observed 38,823 Norwegian women and found that low HDL-C may be associated with a $25 \%$ higher risk of BC versus a high HDL-C. However, a prospective study of 288,057 women conducted by Strohmaier et al. [49] came to the opposite conclusion, i.e., that women with a lower serum cholesterol had a lower risk of BC. In recent years, hypertension and $\mathrm{BC}$ have been the focus of research, but no definite conclusion regarding the possible relationship between hypertension and BC has been found. In 1988, Törnberg et al. [50] found that hypertension was associated with an increased BC risk, while Lindgren et al. [51] reported no effect of hypertension on the incidence of postmenopausal BC compared with the general population at the same age in a 27 -year prospective study. Another casecontrol study showed that hypertension increased BC incidence, and the earlier the onset of hypertension ( $<50$ years), the more obvious was the increase in $\mathrm{BC}$ incidence [52]. In this systematic review, we demonstrated that it is controversial whether MetS had a relationship with $\mathrm{BC}$ in patients with $1 \mathrm{MetS}$ component. However, when patients had several MetS components, MetS increased the risk for BC.

The mechanism by which MetS increase the incidence of $\mathrm{BC}$ is still under exploration. Insulin resistance may be one of the reasons. Insulin is the main hormone that stimulates cell proliferation, and it directly promotes the proliferation of breast tissue and tumor cells, thus possibly promoting BC incidence. Besides, insulin promotes tumor cell proliferation by upregulating insulin-like growth factor 1 (IGF-1), which increases mitotic activity in tumor cells [53, 54]. Adiponectin, also known as adipocyte-associated protein, promotes glucose and fatty acid metabolism, and also improves insulin sensitivity and resistance. Adiponectin is reduced in patients with obesity, diabetes, and coronary heart disease, and a high adiponectin level is associated with lower mortality in BC patients with lower level [45]. Moreover, adiponectin was able to exert an antitumor effect by inhibiting aromatase in estrogen receptor-positive BC patients. The effect of low serum adiponectin on tumor angiogenesis is attenuated, which in turn promotes $\mathrm{BC}$ [55]. In obese postmenopausal BC patients, adipose tissue is the main source of estrogen production. Estradiol is converted from androgen by aromatization of the cytochrome $\mathrm{P}_{450}$ enzyme system present in adipose tissue. Adipocytes secrete IL- 6 and TNF- $\alpha$, which induce aromatization together with prostaglandins. Thus, obesity can increase the production of cytokines and thereby stimulate aromatization to increase estradiol. Estradiol also reduces adiponectin production, thereby attenuating the antitumor effect of adiponectin. Sex hormone-binding globulins (SHBG) are glycoproteins produced by the liver that bind to

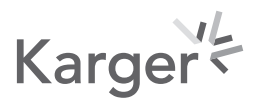


Zhao et al.: MetS Is a Risk Factor for BC

and transport most of the biologically active androgens and estrogens in the circulation, attenuating the effects of these hormones; hyperinsulinemia and IGF-1 inhibit SHBG synthesis, which can in turn impair SHBG production, thus inducing a vicious circle [56]. Our study demonstrated that the postmenopausal status was a crucial factor, which indicated a significant increase in the risk of BC when patients had a diagnosis of MetS. Screening patients with metabolic disorders for $\mathrm{BC}$ is important for early $\mathrm{BC}$ detection, especially for females in the menopausal period. Figuring out the relationship between MetS and $\mathrm{BC}$ can provide clues for the epidemiology of $\mathrm{BC}$, and then lay a foundation to prevent and treat $\mathrm{BC}$.

There were some limitations to our study. Firstly, only observational studies could be designed to study the relationship between MetS and BC, which weakened the quality of the evidence and classified it as "low quality" according to the GRADE criteria. Secondly, there still existed heterogeneity even though we had undertaken subgroup analysis. However, due to the lack of studies which focused on 1 component and cancer type, the heterogeneity could not be avoided in the present meta-analysis. Thirdly, though we have included a large scale of participants and BC patients, this study was not a meta-analysis based on "individual patients," thus a lot of important data was lost on reviewing manuscripts. Further metaanalyses and regressions of individual patients need to be done to clarify the risk of MetS in $\mathrm{BC}$ patients.

\section{Conclusion}

Our study demonstrated that MetS is highly associated with the risk of BC. For postmenopausal female patients with $\geq 2$ components of MetS, or a combination of obesity, hypertension, and diabetes, routine $\mathrm{BC}$ screening could help to detect $\mathrm{BC}$ at an early stage.

\section{Acknowledgment}

This study was supported by a self-raised project (Guangxi Provincial Department of Health Funding, No. Z20170897).

\section{Statement of Ethics}

Ethics approval was not required for this study because it was based on published studies.

\section{Disclosure Statement}

The authors declare no conflict of interest.

\section{Author Contributions}

Design of the meta-analysis: Ping Zhao, Ning Xia.

Literature screening: Ping Zhao, Ning Xia, Hong Zhang.

Quality assessment: Ping Zhao, Ning Xia, Tingting Zhang.

Statistical analysis: Ping Zhao, Ning Xia.

Writing and revision: Ping Zhao, Ning Xia, Hong Zhang, and Tingting Zhang.

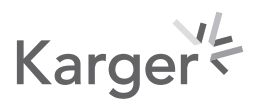




\begin{tabular}{|c|c|}
\hline \multicolumn{2}{|l|}{ Obes Facts 2020;13:384-396 } \\
\hline DOI: 10.1159/000507554 & $\begin{array}{l}\text { (c) } 2020 \text { The Author(s). Published by S. Karger AG, Base } \\
\text { www.karger.com/ofa }\end{array}$ \\
\hline
\end{tabular}

Zhao et al.: MetS Is a Risk Factor for BC

\section{References}

1 Siegel RL, Miller KD, Jemal A. Cancer Statistics, 2017. CA Cancer J Clin. 2017 Jan;67(1):7-30.

2 Soerjomataram I, Lortet-Tieulent J, Parkin DM, Ferlay J, Mathers C, Forman D, et al. Global burden of cancer in 2008: a systematic analysis of disability-adjusted life-years in 12 world regions. Lancet. 2012 Nov;380(9856): 1840-50.

3 Yoo KY, Kim Y, Park SK, Kang D. Lifestyle, genetic susceptibility and future trends of breast cancer in Korea. Asian Pac J Cancer Prev. 2006 Oct-Dec; 7(4):679-82.

4 Chen W, Zheng R, Baade PD, Zhang S, Zeng H, Bray F, et al. Cancer statistics in China, 2015. CA Cancer J Clin. 2016 Mar-Apr;66(2):115-32.

5 Fan L, Strasser-Weippl K, Li JJ, St Louis J, Finkelstein DM, Yu KD, et al. Breast cancer in China. Lancet Oncol. 2014 Jun;15(7):e279-89.

6 Alexander CM, Landsman PB, Teutsch SM, Haffner SM; Third National Health and Nutrition Examination Survey (NHANES III); National Cholesterol Education Program (NCEP). NCEP-defined metabolic syndrome, diabetes, and prevalence of coronary heart disease among NHANES III participants age 50 years and older. Diabetes. 2003 May;52(5):1210-4.

7 Expert Panel on Detection, Evaluation, and Treatment of High Blood Cholesterol in Adults. Executive Summary of The Third Report of The National Cholesterol Education Program (NCEP) Expert Panel on Detection, Evaluation, And Treatment of High Blood Cholesterol In Adults (Adult Treatment Panel III). JAMA. 2001 May; 285(19):2486-97.

8 Khunti K, Davies M. Metabolic syndrome. BMJ. 2005 Nov;331(7526):1153-4.

9 Ford ES, Giles WH, Mokdad AH. Increasing prevalence of the metabolic syndrome among u.s. Adults. Diabetes Care. 2004 Oct;27(10):2444-9.

10 Song QB, Zhao Y, Liu YQ, Zhang J, Xin SJ, Dong GH. Sex difference in the prevalence of metabolic syndrome and cardiovascular-related risk factors in urban adults from 33 communities of China: the CHPSNE study. Diab Vasc Dis Res. 2015 May;12(3):189-98.

11 Eckel RH, Grundy SM, Zimmet PZ. The metabolic syndrome. Lancet. 2005 Apr;365(9468):1415-28.

12 Watanabe J, Kakehi E, Kotani K, Kayaba K, Nakamura Y, Ishikawa S: Metabolic syndrome is a risk factor for cancer mortality in the general Japanese population: the Jichi Medical School Cohort Study. Diabetol Metab Syndr. 2019 Jan 9;11:3.

13 Gathirua-Mwangi WG, Song Y, Monahan PO, Champion VL, Zollinger TW. Associations of metabolic syndrome and C-reactive protein with mortality from total cancer, obesity-linked cancers and breast cancer among women in NHANES III. Int J Cancer. 2018 Aug;143(3):535-42.

14 Park B, Kong SY, Lee EK, Lee MH, Lee ES. Metabolic syndrome in breast cancer survivors with high carbohydrate consumption: the first report in community setting. Clin Nutr. 2017 Oct;36(5):1372-7.

15 Lee JA, Yoo JE, Park HS. Metabolic syndrome and incidence of breast cancer in middle-aged Korean women: a nationwide cohort study. Breast Cancer Res Treat. 2017 Apr;162(2):389-93.

16 Dibaba DT, Ogunsina K, Braithwaite D, Akinyemiju T. Metabolic syndrome and risk of breast cancer mortality by menopause, obesity, and subtype. Breast Cancer Res Treat. 2019 Feb;174(1):209-18.

17 Wu YT, Luo QQ, Li X, Arshad B, Xu Z, Ran L, et al. Clinical study on the prevalence and comparative analysis of metabolic syndrome and its components among Chinese breast cancer women and control population. J Cancer. 2018 Jan;9(3):548-55.

18 Kabat GC, Kim M, Chlebowski RT, Khandekar J, Ko MG, McTiernan A, et al. A longitudinal study of the metabolic syndrome and risk of postmenopausal breast cancer. Cancer Epidemiol Biomarkers Prev. 2009 Jul;18(7): 2046-53.

19 Moher D, Liberati A, Tetzlaff J, Altman DG, PRISMA Group. Preferred reporting items for systematic reviews and meta-analyses: the PRISMA statement. PLoS Med. 2009 Jul;6(7):e1000097.

20 Stang A. Critical evaluation of the Newcastle-Ottawa scale for the assessment of the quality of nonrandomized studies in meta-analyses. Eur J Epidemiol. 2010 Sep;25(9):603-5.

21 Balshem H, Helfand M, Schünemann HJ, Oxman AD, Kunz R, Brozek J, et al. GRADE guidelines: 3. Rating the quality of evidence. J Clin Epidemiol. 2011 Apr;64(4):401-6.

22 Fang Q, Tong YW, Wang G, Zhang N, Chen WG, Li YF, et al. Neutrophil-to-lymphocyte ratio, obesity, and breast cancer risk in Chinese population. Medicine (Baltimore). 2018 Jul;97(30):e11692.

23 Kabat GC, Kim MY, Lee JS, Ho GY, Going SB, Beebe-Dimmer J, et al. Metabolic Obesity Phenotypes and Risk of Breast Cancer in Postmenopausal Women. Cancer Epidemiol Biomarkers Prev. 2017 Dec;26(12):1730-5.

24 Ko S, Yoon SJ, Kim D, Kim AR, Kim EJ, Seo HY. Metabolic risk profile and cancer in Korean men and women. J Prev Med Public Health. 2016 May;49(3):143-52.

25 Bitzur R, Brenner R, Maor E, Antebi M, Ziv-Baran T, Segev S, et al. Metabolic syndrome, obesity, and the risk of cancer development. Eur J Intern Med. 2016 Oct;34:89-93.

26 Wang M, Cheng N, Zheng S, Wang D, Hu X, Ren X, et al. Metabolic syndrome and the risk of breast cancer among postmenopausal women in North-West China. Climacteric. 2015;18(6):852-8.

27 Shin JY, Choi YH, Song YM. Metabolic Syndrome in Korean Cancer Survivors and Family Members: A Study in a Health Promotion Center. Nutr Cancer. 2015;67(7):1075-82.

28 Agnoli C, Grioni S, Sieri S, Sacerdote C, Ricceri F, Tumino R, et al. Metabolic syndrome and breast cancer risk: a case-cohort study nested in a multicentre italian cohort. PLoS One. 2015 Jun;10(6):e0128891.

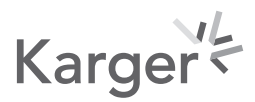


Zhao et al.: MetS Is a Risk Factor for BC

29 van Kruijsdijk RC, van der Graaf Y, Peeters PH, Visseren FL; Second Manifestations of ARTerial disease (SMART) study group. Cancer risk in patients with manifest vascular disease: effects of smoking, obesity, and metabolic syndrome. Cancer Epidemiol Biomarkers Prev. 2013 Jul;22(7):1267-77.

30 Noh HM, Song YM, Park JH, Kim BK, Choi YH. Metabolic factors and breast cancer risk in Korean women. Cancer Causes Control. 2013 Jun;24(6):1061-8.

31 Capasso I, Esposito E, Pentimalli F, Montella M, Crispo A, Maurea N, et al. Homeostasis model assessment to detect insulin resistance and identify patients at high risk of breast cancer development: National Cancer Institute of Naples experience. J Exp Clin Cancer Res. 2013 Mar;32(1):14.

32 Buttros DA, Nahas EA, Vespoli HL, Uemura G, de Almeida BR, Nahas-Neto J. Risk of metabolic syndrome in postmenopausal breast cancer survivors. Menopause. 2013 Apr;20(4):448-54.

33 Ronco AL, De Stefani E, Deneo-Pellegrini H, Quarneti A. Diabetes, overweight and risk of postmenopausal breast cancer: a case-control study in Uruguay. Asian Pac J Cancer Prev. 2012;13(1):139-46.

34 Reeves KW, McLaughlin V, Fredman L, Ensrud K, Cauley JA. Components of metabolic syndrome and risk of breast cancer by prognostic features in the study of osteoporotic fractures cohort. Cancer Causes Control. 2012 Aug;23(8):1241-51.

35 Osaki Y, Taniguchi S, Tahara A, Okamoto M, Kishimoto T. Metabolic syndrome and incidence of liver and breast cancers in Japan. Cancer Epidemiol. 2012 Apr;36(2):141-7.

36 Rosato V, Bosetti C, Talamini R, Levi F, Montella M, Giacosa A, et al. Metabolic syndrome and the risk of breast cancer in postmenopausal women. Ann Oncol. 2011 Dec;22(12):2687-92.

37 Bordeleau L, Lipscombe L, Lubinski J, Ghadirian P, Foulkes WD, Neuhausen S, et al.; Hereditary Breast Cancer Clinical Study Group. Diabetes and breast cancer among women with BRCA1 and BRCA2 mutations. Cancer. 2011 May;117(9):1812-8.

38 Fagherazzi G, Fabre A, Boutron-Ruault MC, Clavel-Chapelon F. Serum cholesterol level, use of a cholesterollowering drug, and breast cancer: results from the prospective E3N cohort. Eur J Cancer Prev. 2010 Mar;19(2): 120-5.

39 Chen TH, Chiu YH, Luh DL, Yen MF, Wu HM, Chen LS, et al.; Taiwan Community-Based Integrated Screening Group. Community-based multiple screening model: design, implementation, and analysis of 42,387 participants. Cancer. 2004 Apr;100(8):1734-43.

40 Bhaskaran K, Douglas I, Forbes H, dos-Santos-Silva I, Leon DA, Smeeth L. Body-mass index and risk of 22 specific cancers: a population-based cohort study of 5.24 million UK adults. Lancet. 2014 Aug;384(9945): 755-65.

41 Rose DP, Vona-Davis L. Interaction between menopausal status and obesity in affecting breast cancer risk. Maturitas. 2010 May;66(1):33-8.

42 Connolly BS, Barnett C, Vogt KN, Li T, Stone J, Boyd NF. A meta-analysis of published literature on waist-to-hip ratio and risk of breast cancer. Nutr Cancer. 2002;44(2):127-38.

43 Renehan AG, Tyson M, Egger M, Heller RF, Zwahlen M. Body-mass index and incidence of cancer: a systematic review and meta-analysis of prospective observational studies. Lancet. 2008 Feb;371(9612):569-78.

44 Park YM, White AJ, Nichols HB, O’Brien KM, Weinberg CR, Sandler DP. The association between metabolic health, obesity phenotype and the risk of breast cancer. Int J Cancer. 2017 Jun;140(12):2657-66.

45 Kabat GC, Kim M, Caan BJ, Chlebowski RT, Gunter MJ, Ho GY, et al. Repeated measures of serum glucose and insulin in relation to postmenopausal breast cancer. Int J Cancer. 2009 Dec;125(11):2704-10.

46 Boyle P, Boniol M, Koechlin A, Robertson C, Valentini F, Coppens K, et al. Diabetes and breast cancer risk: a meta-analysis. Br J Cancer. 2012 Oct;107(9):1608-17.

47 Kitahara CM, Berrington de González A, Freedman ND, Huxley R, Mok Y, Jee SH, et al. Total cholesterol and cancer risk in a large prospective study in Korea. J Clin Oncol. 2011 Apr;29(12):1592-8.

48 Furberg AS, Veierød MB, Wilsgaard T, Bernstein L, Thune I. Serum high-density lipoprotein cholesterol, metabolic profile, and breast cancer risk. J Natl Cancer Inst. 2004 Aug;96(15):1152-60.

49 Strohmaier S, Edlinger M, Manjer J, Stocks T, Bjørge T, Borena W, et al. Total serum cholesterol and cancer incidence in the Metabolic syndrome and Cancer Project (Me-Can). PLoS One. 2013;8(1):e54242.

50 Törnberg SA, Holm LE, Carstensen JM. Breast cancer risk in relation to serum cholesterol, serum beta-lipoprotein, height, weight, and blood pressure. Acta Oncol. 1988;27(1):31-7.

51 Lindgren AM, Nissinen AM, Tuomilehto JO, Pukkala E. Cancer pattern among hypertensive patients in North Karelia, Finland. J Hum Hypertens. 2005 May;19(5):373-9.

52 Largent JA, McEligot AJ, Ziogas A, Reid C, Hess J, Leighton N, et al. Hypertension, diuretics and breast cancer risk. J Hum Hypertens. 2006 Oct;20(10):727-32.

53 Kwan ML, Kushi LH, Weltzien E, Tam EK, Castillo A, Sweeney C, et al. Alcohol consumption and breast cancer recurrence and survival among women with early-stage breast cancer: the life after cancer epidemiology study. J Clin Oncol. 2010 Oct;28(29):4410-6.

54 Giovannucci E. Insulin, insulin-like growth factors and colon cancer: a review of the evidence. J Nutr. 2001 Nov; 131(11 Suppl):3109S-20S.

55 Nechushtan H, Vainer G, Stainberg H, Salmon AY, Hamburger T, Peretz T. A phase 1/2 of a combination of cetuximab and taxane for "triple negative" breast cancer patients. Breast. 2014 Aug;23(4):435-8.

56 Calle EE, Kaaks R. Overweight, obesity and cancer: epidemiological evidence and proposed mechanisms. Nat Rev Cancer. 2004 Aug;4(8):579-91. 